\title{
Preoperative diagnostic of parotid gland neoplasms: fine-needle aspiration cytology or core needle biopsy?
}

\author{
Peter Zbären ${ }^{1}(\mathbb{1}) \cdot$ Asterios Triantafyllou $^{2,3} \cdot$ Kenneth O. Devaney ${ }^{4} \cdot$ Vincent Vander Poorten $^{5,6} \cdot$ Henrik Hellquist $^{7}$. \\ Alessandra Rinaldo ${ }^{8}$. Alfio Ferlito ${ }^{9}$
}

Received: 27 July 2018 / Accepted: 11 September 2018 / Published online: 20 September 2018

c) Springer-Verlag GmbH Germany, part of Springer Nature 2018

\begin{abstract}
A preoperative cytologic or histologic diagnosis of parotid gland neoplasms is mandatory to decide which surgical procedure would be appropriate. Open biopsies are contraindicated because of the risk of recurrence secondary to tumour cell seeding; furthermore a subsequent curative parotid surgery can be complicated by a previous open biopsy. While fine-needle aspiration cytology (FNAC) was the only preoperative diagnostic procedure to distinguish benign versus malignant neoplasms over the past decades, core needle biopsy (CNB) has been increasingly used over the last few years. This created a debate as to whether FNAC or CNB should be the preoperative procedure of choice. The focus of this editorial is to analyse the advantages and disadvantages of FNAC and CNB, and to discuss which procedure is more appropriate in the preoperative work-up of parotid neoplasms.
\end{abstract}

This article was written by members of the International Head and Neck Scientific Group (http://www.IHNSG.com).

\section{Peter Zbären}

peter.zbaeren@insel.ch

1 Department of Otorhinolaryngology, Head and Neck Surgery, University Hospital, Bern, Switzerland

2 Cellular Pathology, Liverpool Clinical Laboratories, Royal Liverpool University Hospital, Liverpool, UK

3 School of Dentistry, University of Liverpool, Liverpool, UK

4 Department of Pathology, Allegiance Health, Jackson, MI, USA

5 Section Head and Neck Oncology, Otorhinolaryngology-Head and Neck Surgery and Department of Oncology, University Hospitals Leuven, KU Leuven, Leuven, Belgium

6 European Salivary Gland Society, Geneva, Switzerland

7 Centre of Biomedical Research (CBMR), Department of Biomedical Sciences and Medicine, University of Algarve, Faro, Portugal

8 University of Udine School of Medicine, Udine, Italy

9 International Head and Neck Scientific Group, Padua, Italy

\section{Introduction}

Salivary gland masses encompass a wide range of non-neoplastic lesions and of benign and malignant neoplasms. The malignancy rate for parotid tumours has been reported to be between 14-27\% [1-3]. Age-standardized incidence rates per 100,000 in the US are 1.0 for males and 0.7 for females [4]. Signs and symptoms of malignancy such as pain, facial palsy and enlarged lymph nodes are present in approximately $25-35 \%$ of patients $[5,6]$. After initial ultrasound evaluation, MR imaging is the modality of choice in the work-up of parotid neoplasms [7-9] if an additional imaging study is useful or necessary. Poorly defined tumour margins are the most accurate indicator of malignancy. However, such margins are present in up to $50 \%$ of malignant tumours on MR imaging [7], and small malignant neoplasms often resemble benign tumours on imaging studies $[10,11]$. Neither clinical examination nor imaging studies can substitute for fineneedle aspiration cytology (FNAC) or core needle biopsy (CNB) in the preoperative diagnosis of parotid malignancies. Open biopsies are contraindicated because of the risk of tumour cell seeding, increasing the risk of recurrence of both malignant neoplasms and pleomorphic adenomas; furthermore, a subsequent curative parotid surgery can be complicated by a previous open biopsy [5]. Before 2000, all parotid neoplasms were treated by a formal parotidectomy: benign parotid neoplasms in the superficial lobe by 
a superficial parotidectomy and in the deep lobe by a total parotidectomy; malignant epithelial neoplasms were treated at least by a total parotidectomy. As the surgical options were restricted, the necessity and benefits of FNAC were questioned at that time [12]. But over the last two decades, new surgical procedures for benign tumours such as extracapsular dissection, partial superficial parotidectomy or deep lobe parotidectomy with preservation of the superficial lobe have been introduced [13-18]. Thus, in deciding which surgical procedure would be appropriate, it should be-whenever possible-known at the time of surgery whether the tumour to treat is, for example, a pleomorphic adenoma or a malignant neoplasm. For malignant neoplasms, it would be also desirable to know the histologic tumour type and grade since for several low-grade carcinomas, a deep-lobe parotidectomy can be avoided [19]. At present, the question is no longer-as 20-30 years ago-whether a preoperative cyto-/ histo-logic diagnostic procedure is necessary and useful, but, which is more appropriate: FNAC or CNB. This is currently debated among head and neck surgeons and pathologists.

The present editorial aims to summarize the advantages and disadvantages of FNAC and CNB, and to discuss which of these preoperative diagnostic procedure may be the procedure of choice.

\section{Fine-needle aspiration cytology}

In experienced hands, FNAC is easy to perform and can be done in an outpatient setting with a 25-22 gauge needle; it causes little pain, does not require local anaesthesia and allows only limited histo/immunohisto-chemical analysis of the obtained material. Numerous studies on the utility and accuracy of FNAC have been published. Most of these are however retrospective and often do not mention whether samples are obtained by pathologists, radiologists or clinicians, nor whether the procedure is guided via palpation or ultrasound. In many studies, neither the sample removal technique nor the experiences and number of operators and pathologists involved are reported. In some studies, nonneoplastic lesions or recurrences of neoplasms are included while in others, they are not. On these grounds, it is difficult to compare the FNAC results.

\section{Reported results}

In 2011, Schmidt et al. [20] published "a systematic review and meta-analysis of the diagnostic accuracy of FNAC for parotid gland lesions". They included 7 datasets for the assessment of non-neoplastic versus neoplastic lesions, with a total of 795 cases, and 64 datasets on the accuracy of FNAC for the diagnostic of malignancy versus benignancy, with a total of 6169 cases; 530 inadequate or indeterminate
FNACs (8.6\%) were reported. In distinguishing neoplastic from non-neoplastic lesions, the sensitivity and specificity were $96 \%$ and $98 \%$, respectively. As for the distinction of malignant versus benign lesions, the sensitivity and specificity were $80 \%$ and $97 \%$, respectively. They concluded that FNAC shows a quite high specificity for the diagnosis of neoplasia (98\%) and malignancy (97\%). The 64 analysed studies show more variability of sensitivity $(33-100 \%)$ than specificity (88-100\%), except one study with a specificity of $67 \%$. A later meta-analysis performed by Liu et al. [21] included 70 studies with 6784 FNACs and reported 518 nondiagnostic and 385 indeterminate findings (13.3\%). For the diagnostic of malignancy versus benignancy, 63 studies with 5647 FNACs were included. The sensitivity and specificity were $78 \%$ and $98 \%$, respectively. In addition, Feinstein et al. [22] analysed 272 FNACs of parotid and 71 of submandibular neoplasms. There were 22 non-diagnostic and 39 indeterminate specimens (17.8\%). The sensitivity and specificity in the detection of malignant neoplasms were for parotid $75 \%$ and $95 \%$ and for submandibular $91 \%$ and $94 \%$, respectively. The most recent analysis, published in 2018 [23], included 477 parotid FNACs and reported a sensitivity and specificity for detecting malignancy of $82 \%$ and $90 \%$, respectively. In $26(5.5 \%)$ cases, the FNAC was non-diagnostic. There were $26(5.5 \%)$ false-negative and $29(6.4 \%)$ false-positive findings. The higher rate of false positives is in contrast to most studies reporting higher rates of false-negative than false-positive findings [24-27]. It is emphasized that only a few studies analysed tumour typing: the reported accuracy is $18-35 \%[26,28]$.

\section{Complications}

Major complications such as tumour cell seeding or facial nerve paresis appear extremely rare. Shah et al. [29] analysed 575 studies including a total of 41,468 FNACs of head and neck masses. Only five cases of seeding were documented, three of which after FNAC of the parotid gland, thus corresponding to a risk of seeding of $0.00012 \%$. The factors influencing the risk of cell seeding may be the needle size, the number of passes and the use of suction or capillary technique [29]. Interestingly, the risk of cell seeding seems to be greater in other organs such as thyroid gland $(0.14 \%)$ [30] and liver (0.13\%) [31]. There are no reported cases of facial nerve paresis after FNAC of the parotid gland.

\section{Discussion (FNAC)}

FNAC may be considered a safe and cost-effective procedure, with an extremely low rate of complications. The FNAC procedure does not require local anaesthesia but it is characterized by a relatively high rate of non-diagnostic and intermediate findings. The accuracy of FNAC 
results is strongly related to the experience of the operator and cytologist. For distinguishing neoplastic versus non-neoplastic pathologies, the sensitivity and specificity of FNAC are high whereas for distinguishing malignant versus benign neoplasms, the sensitivity is much less satisfactory. The accuracy of tumour typing and grading is low. Possibly, histologic type, frequency of unusual lesions and experience of the cytologist influence these results. Accordingly, FNAC can be inappropriate to guide the extent of surgery for malignant neoplasms of the parotid gland. The accuracy of FNAC seems to be increased by an on-site microscopic evaluation of aspirates performed by a cytologist $[32,33]$ as well as by systematic ultrasound guidance. But it may be difficult in the daily practice, to have a cytologist available and most head and neck oncologists do not perform ultrasound examinations themselves.

\section{Core needle biopsy}

For many decades, core needle biopsies have been used in various oncological fields such as urology, hepatology, or breast diseases as an alternative to open biopsies. During the last decade, there has been a rise in the use of CNB for parotid gland lesions. CNB aims at obtaining an adequate sample of tissue with preserved histological architecture. This would enable the pathologist to apply a wider range of histochemical stains and immunohistochemical techniques, which may assist in tumour typing and grading in many cases [34]. Even extracapsular tumour growth has been occasionally detected in CNB specimens [35] but this is influenced by chance. The CNB is performed under ultrasound guidance after local anaesthesia with an 20-17 gauge needle, depending on the tumour size, localisation and the suspected disease process (e.g., lymphoma) [36].

\section{Reported results}

Kim et al. [37] in 2018 reported an update of two previous meta-analyses $[34,38]$ and a systematic review which included ten articles published between 2005 and 2016, encompassing $1315 \mathrm{CNBs}$. The rate of non-diagnostic specimens was $3.6 \%$ (46 out of 1268)-in one article the incidence of non-diagnostic specimens was not mentioned. There were 18 (1.3\%) false-positive and 26 (2\%) falsenegative findings. The pooled sensitivity and specificity in detecting malignant neoplasms were $94 \%$ and $98 \%$, respectively. In the two previous meta-analyses [34, 38] of CNB, the accuracy of specific histologic diagnosis was reported to be $96 \%$ and $95 \%$.

\section{Complications}

In the meta-analysis by Kim [37], which as stated above included 1315 CNBs, 7 (0.5\%) haematomas occurred and neither cell seeding nor permanent facial nerve paresis were reported; in one case, a temporary facial nerve weakness caused by local anesthesia was described. In 2016, Shah et al. [29] analysed 35 articles including 1803 CNB's of head and neck masses; only 2 cases of seeding were reported: one in the parotid gland [39] and one in a lymph node [40]. In 2016, Novoa et al. [41] investigated 103 excised needle tracks after CNB of salivary gland lesions, most located in the parotid gland. The examination revealed no tumour displacement in 65 cases and in 38 cases, the needle track was not identified.

\section{Discussion (CNB)}

With the use of CNB, a sample of tissue with preserved histological architecture is obtained. The rate of indeterminate or inadequate specimens is low; the sensitivity and specificity in detecting malignant versus benign neoplasms are high. CNB is accurate in distinguishing carcinoma from lymphoma and, often, in tumour typing and grading. The procedure requires a local anaesthesia. Major complications are rarely reported but further data is desirable. The risk of tumour cell seeding after CNB seems to be related to the needle diameter, the tumour type and the anatomic site of puncture [42]. While needle track recurrences after CNB of breast cancer, thyroid cancer, etc., are described in the literature [43], no such recurrences after CNB of parotid gland neoplasms have been reported. Authors who are reluctant to endorse regular use of CNB argue that the number of analysed CNBs of parotid gland neoplasms may be too small and the follow-up too short for detecting needle track recurrences.

The risk of injuries of facial nerve branches may potentially be increased in CNBs of neoplasms in the periphery of the parotid, where nerve branches are quite superficial and in some cases lateral to the neoplasm. However, such lesions were never reported.

\section{Comparison between FNAC and CNB}

CNB is superior to FNAC in the preoperative diagnosis of parotid masses. CNB has a higher sensitivity in diagnosing malignant neoplasms and allows tumour typing and grading in most cases. The specificity of both procedures for discriminating benign from malignant lesions is quite similar. The rate of indeterminate and non-diagnostic specimens is lower with CNB than with FNAC. CNB requires a local anaesthesia and is, therefore, more time-consuming than FNAC. The number of passes is generally higher in 
FNAC than in CNB. The rate of major complications such as tumour cell seeding or facial nerve paresis is extremely low for both procedures. Several authors $[44,45]$ who performed both FNAC and CNB compared their own experience in retrospective studies and made the same observations. Novoa et al. [41] analysed in 2016 in a prospective study comparing FNAC with CNB 103 patients with salivary gland lesions; they received ultrasound-guided FNAC and CNB; a cytologist was present during the FNAC procedure. The sensitivity and specificity in detecting malignant neoplasms for FNAC and CNB were 64 and $94 \%$ versus 95 and 100\%. The results of CNB were clearly superior to that of FNAC despite ultrasound guidance and in situ of a cytologist during the latter.

\section{Conclusions}

Due to the rarity of malignant salivary gland neoplasms, the variety of carcinoma types and the similarity of several cytological findings of benign tumours and low-grade carcinomas, FNAC diagnosis is challenging; optimal evaluation requires cytologists experienced in salivary pathology. Since FNAC has a high specificity and a high sensitivity in distinguishing non-neoplastic lesions versus neoplastic masses, it could be used as first diagnostic procedure in lesions with a low probability to be a neoplasm.

In the preoperative diagnosis of parotid neoplasms, CNB is superior to FNAC. CNB preserves tissue architecture allowing a wider range of histochemical and immunohistochemical techniques than FNAC; the microscopical assessment should be performed by head and neck pathologists preferably with proven record in salivary glands. CNB has a high diagnostic potential (tumour typing and grading) compared to frozen section (FS) [28, 38, 46], thus, intraoperative FS may be avoided in selected cases by performing a preoperative $\mathrm{CNB}$, which could diminish costs and allow optimal planning of surgery and counselling of the patient. Finally, the evolving molecular testing in the diagnosis of salivary gland neoplasms seems feasible with CNB material [47, 48]. A disadvantage of CNB is the local anaesthesia, with greater time consumption and discomfort for the patient.

Nevertheless, CNB may be the procedure of choice in the preoperative work-up of parotid neoplasms; it must be performed by experienced operators as sonographic examination of head and neck is recognized as challenging. Furthermore, in case of pleomorphic adenoma or malignant neoplasm, the needle track may be resected during curative surgery [41].

It is noted, that relevant current knowledge is based mainly on retrospective studies variously performed: ultrasound versus palpation guided and different specialists involved (pathologists, clinicians or radiologists). Furthermore, the experience and number of involved operators and pathologists, as well as the size of the needle and the number of passes, are not mentioned in many studies. Schmidt RL et al. [49] analysed 95 studies on FNAC or CNB and concluded that verification bias is common; most analyses overestimated sensitivity and underestimated specificity.

A prospective study with a statistically optimal number of cases of both FNAC and CNB and a precisely defined protocol (inclusion criteria; experience of operators and pathologists; needle size; number of passes, etc.) is needed to properly evaluate the ideal use of FNAC and CNB in the work-up of parotid masses. Furthermore, detailed histopathological evaluation of needle tracks of both FNAC and CNB are desirable.

\section{Compliance with ethical standards}

Conflict of interest All authors declare that they have no conflict of interest.

\section{References}

1. Frankenthaler RA, Luna MA, Lee SS, Ang K-K, Byers RM, Guillamondegui OM et al (1991) Prognostic variables in parotid gland cancer. Arch Otolaryngol Head Neck Surg 117(11):1251-1256

2. Spiro RH (1986) Salivary neoplasms: overview of a 35-year experience with 2,807 patients. Head Neck Surg 8(3):177-184

3. Gallo O, Franchi A, Bottai GV, Fini-Storchi I, Tesi G, Boddi V (1997) Risk factors for distant metastases from carcinoma of the parotid gland. Cancer 80(5):844-851

4. Parkin D, Whelan S, Ferlay J, Teppo L, Thomas D (2002) Cancer incidence in five continents. IARC Sci Publ 8(143):1-1240

5. Vander Poorten V, Bradley PJ, Takes RP, Rinaldo A, Woolgar JA, Ferlito A (2012) Diagnosis and management of parotid carcinoma with a special focus on recent advances in molecular biology. Head Neck 34(3):429-440

6. Wong DS (2001) Signs and symptoms of malignant parotid tumours: an objective assessment. J R Coll Surg Edinb 46(2):91-95

7. Freling NJ, Molenaar WM, Vermey A, Mooyaart EL, Panders AK, Annyas AA et al (1992) Malignant parotid tumors: clinical use of MR imaging and histologic correlation. Radiology 185(3):691-696

8. Bartels S, Talbot JM, DiTomasso J, Everts EC, Andersen PE, Wax MK et al (2000) The relative value of fine-needle aspiration and imaging in the preoperative evaluation of parotid masses. Head Neck 22(8):781-786

9. Barsotti JB, Westesson PL, Coniglio JU (1994) Superiority of magnetic resonance over computed tomography for imaging parotid tumor. Ann Otol Rhinol Laryngol 103(9):737-740

10. Zbären P, Zbären S, Caversaccio MD, Stauffer E (2008) Carcinoma ex pleomorphic adenoma: diagnostic difficulty and outcome. Otolaryngol Head Neck Surg 138(5):601-605

11. Mantsopoulos K, Koch M, Iro H (2017) Extracapsular dissection as sole therapy for small low-grade malignant tumors of the parotid gland. Laryngoscope 127(8):1804-1807

12. Batsakis J, Sneige N, el-Naggar A (1992) Fine-needle aspiration of salivary glands: it's utility and effects. Ann Otol Rhinol Laryngol 101:185-188

13. Witt RL (2002) The significance of the margin in parotid surgery for pleomorphic adenoma. Laryngoscope 112(12):2141-2154 
14. Vaiman M, Abuita R, Jabarin B (2015) Selective deep lobe parotid surgery for benign tumors. Acta Otolaryngol 135(12):1319-1322

15. Hussain A, Murray DP (2005) Preservation of the superficial lobe for deep-lobe parotid tumors: a better aesthetic outcome. Ear Nose Throat J 84(8):518-524

16. McGurk M, Thomas BL, Renehan AG (2003) Extracapsular dissection for clinically benign parotid lumps: reduced morbidity without oncological compromise. Br J Cancer 89(9):1610-1613

17. Zbären P, Vander Poorten V, Witt RL, Woolgar JA, Shaha AR, Triantafyllou A et al (2013) Pleomorphic adenoma of the parotid: formal parotidectomy or limited surgery? Am J Surg 205:109-118

18. Quer M, Guntinas-Lichius O, Marchal F, Vander Poorten V, Chevalier D, León X et al (2016) Classification of parotidectomies: a proposal of the European Salivary Gland Society. Eur Arch OtoRhino-Laryngol 273(10):3307-3312

19. Olsen KD, Quer M, de Bree R, Vander Poorten V, Rinaldo A, Ferlito A. Deep lobe parotidectomy - why, when, and how? European Archives of Oto-Rhino-Laryngology. 2017;274(12):4073-4078

20. Schmidt RL, Hall BJ, Wilson ARLL (2011) A systematic review and meta-analysis of the diagnostic accuracy of fine- needle aspiration cytology for parotid gland lesions. Am J Clin Pathol 136(1):45-59

21. Liu CC, Jethwa AR, Khariwala SS, Johnson J, Shin JJ (2016) Sensitivity, specificity, and posttest probability of parotid fine-needle aspiration: a systematic review and meta-analysis. Otolaryngol Head Neck Surg 154(1):9-23

22. Feinstein AJ, Alonso J, Yang SE, John MS (2016) Diagnostic accuracy of fine-needle aspiration for parotid and submandibular gland lesions. Otolaryngol Head Neck Surg 155(3):431-436

23. Eytan DF, Yin LX, Maleki Z, Koch WM, Tufano RP, Eisele DW et al (2018) Utility of preoperative fine needle aspiration in parotid lesions. Laryngoscope 128(2):398-402

24. Zbären P, Nuyens M, Loosli H, Stauffer E (2004) Diagnostic accuracy of fine-needle aspiration cytology and frozen section in primary parotid carcinoma. Cancer 100(9):1876-1883

25. Zurrida S, Alasio L, Pilotti S, Tradati N, Chiesa F, Bartoli C (1993) Fine-needle aspiration of parotid masses. Cancer 72(8):2306-2311

26. Song IH, Song JS, Sung CO, Roh J-L, Choi S-H, Nam SY et al (2015) Accuracy of core needle biopsy versus fine needle aspiration cytology for diagnosing salivary gland tumors. J Pathol Transl Med 49(2):136-143

27. Que Hee CG, Perry CF (2001) Fine-needle aspiration cytology of parotid tumours: is it useful? ANZ J Surg 71(6):345-348

28. Zbären P, Guélat D, Loosli H, Stauffer E (2008) Parotid tumors: fine-needle aspiration and/or frozen section. Otolaryngol Head Neck Surg 139(6):811-815

29. Shah KSV, Ethunandan M (2016) Tumour seeding after fine-needle aspiration and core biopsy of the head and neck-a systematic review. Br J Oral Maxillofac Surg 54:260-265

30. Polyzos SA, Anastasilakis AD (2010) A systematic review of cases reporting needle tract seeding following thyroid fine needle biopsy. World J Surg 34:844-851

31. Tung WC, Huang YJ, Leung SW, Kuo FY, Tung H, Wang JH et al (2007) Incidence of needle tract seeding and responses of soft tissue metastasis by hepatocellular carcinoma postradiotherapy. Liver Int 27(2): 192-200

32. Eisele DW, Sherman ME, Koch WM, Richtsmeier WJ, Wu AY, Erozan YS (1992) Utility of immediate on-site cytopathological procurement and evaluation in fine needle aspiration biopsy of head and neck masses. Laryngoscope 102(12):1328-1330

33. Wu M, Burstein DE, Yuan S, Nurse LA, Szporn AH, Zhang D et al (2006) A comparative study of 200 fine needle aspiration biopsies performed by clinicians and cytopathologists. Laryngoscope 116(7):1212-1215

34. Schmidt RL, Hall BJ, Layfield LJ (2011) A systematic review and meta-analysis of the diagnostic accuracy of ultrasound-guided core needle biopsy for salivary gland lesions. Am J Clin Pathol 136:516-526

35. Breeze J, Andi A, Williams MD, Howlett DC (2009) The use of fine needle core biopsy under ultrasound guidance in the diagnosis of a parotid mass. Br J Oral Maxillofac Surg 47(1):78-79

36. Carbone A, Ferlito A, Devaney KO, Rinaldo A (2008) Ultrasoundguided core-needle biopsy: Is it effective in the diagnosis of suspected lymphomas presenting in the head and neck? J Surg Oncol 98(1):4-5

37. Kim HJ, Kim JS (2018) Ultrasound-guided core needle biopsy in salivary glands: a meta-analysis. Laryngoscope 128(1):118-125

38. Witt BL, Schmidt RL (2014) Ultrasound-guided core needle biopsy of salivary gland lesions: a systematic review and metaanalysis. Laryngoscope 124(3):695-700

39. Yamaguchi KT, Strong MS, Shapshay SM, Soto E (1979) Seeding of parotid carcinoma along Vim-Silverman needle tract. J Otolaryngol 8(1):49-52

40. Kraft M, Laeng H, Schmuziger N, Arnoux A, Gürtler N (2008) Comparison of ultrasound-guided core-needle biopsy and fineneedle aspiration in the assessment of head and neck lesions. Head Neck 30(11):1457-1463

41. Novoa E, Gürtler N, Arnoux A, Kraft M (2016) Diagnostic value of core needle biopsy and fine-needle aspiration in salivary gland lesions. Head Neck 38(suppl 1):E346-E352

42. Kesse KW, Manjaly G, Violaris N, Howlett DC (2002) Ultrasound-guided biopsy in the evaluation of focal lesions and diffuse swelling of the parotid gland. Br J Oral Maxillofac Surg 40(5):384-388

43. Douville NJ, Bradford CR (2013) Comparison of ultrasoundguided core biopsy versus fine-needle aspiration biopsy in the evaluation of salivary gland lesions. Head Neck 35(11):1657-1661

44. Eom HJ, Lee JH, Ko MS, Choi YJ, Yoon RG, Cho KJ et al (2015) Comparison of fine-needle aspiration and core needle biopsy under ultrasonographic guidance for detecting malignancy and for the tissue-specific diagnosis of salivary gland tumors. Am J Neuroradiol 36(6):1188-1193

45. Huang YC, Wu C, Lin G, Chuang WY, Yeow KM, Wan YL (2012) Comparison of ultrasonographically guided fine-needle aspiration and core needle biopsy in the diagnosis of parotid masses. J Clin Ultrasound 40(4):189-194

46. Olsen KD, Moore EJ, Lewis JE (2013) Frozen section pathology for decision making in parotid surgery. JAMA Otolaryngol Head Neck Surg 139(12):1275-1278

47. Skalova A, Stenman G, Simpson RHW, Hellquist H, Slouka D, Svoboda T et al (2018) The role of molecular testing in the differential diagnosis of salivary gland carcinomas. Am J Surg Pathol 42(2): e11-e27

48. Evrard SM, Meilleroux J, Daniel G, Basset C, Lacoste-Collin L, Vergez S et al (2017) Use of fluorescent in-situ hybridisation in salivary gland cytology: a powerful diagnostic tool. Cytopathology 28(4):312-320

49. Schmidt RL, Jedrzkiewicz JD, Allred RJ, Matsuoka S, Witt BL (2014) Verification bias in diagnostic accuracy studies for fine- and core needle biopsy of salivary gland lesions in otolaryngology journals: a systematic review and analysis. Head Neck 36(11):1654-1661 